\title{
ESTIMATION OF SOLAR RADIATION ON BUILDING ROOFS IN MOUNTAINOUS AREAS
}

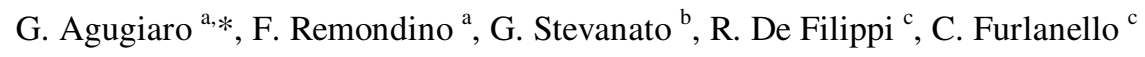 \\ a 3D Optical Metrology Unit, Fondazione Bruno Kessler, Trento, Italy \\ \{agugiaro, remondino\}@fbk.eu, http://3dom.fbk.eu \\ ${ }^{\mathrm{b}}$ Dept. of Architecture, Urban Modelling and Surveying, University of Padova, Italy \\ giulio.stevanato@unipd.it \\ ${ }^{\mathrm{c}}$ Predictive Models for Biomedicine \& Environment Unit, Fondazione Bruno Kessler, Trento, Italy \\ \{defilippi, furlan\}@fbk.eu, http://mpba.fbk.eu
}

Working Groups I/2, III/1, III/4, III/5

KEY WORDS: Photovoltaic potential, 3D buildings, Data integration, GRASS GIS, Photogrammetry, LiDAR, Terrain modelling

\begin{abstract}
:
The aim of this study is estimating solar radiation on building roofs in complex mountain landscape areas. A multi-scale solar radiation estimation methodology is proposed that combines 3D data ranging from regional scale to the architectural one. Both the terrain and the nearby building shadowing effects are considered. The approach is modular and several alternative roof models, obtained by surveying and modelling techniques at varying level of detail, can be embedded in a DTM, e.g. that of an Alpine valley surrounded by mountains. The solar radiation maps obtained from raster models at different resolutions are compared and evaluated in order to obtain information regarding the benefits and disadvantages tied to each roof modelling approach. The solar radiation estimation is performed within the open-source GRASS GIS environment using r.sun and its ancillary modules.
\end{abstract}

\section{INTRODUCTION}

The rising energy costs and the need to reduce carbon-dioxide emissions are intensifying research efforts for alternative, renewable (and sustainable) energy sources.

Solar technology is one of the natural choices for on-site generation as the energy coming from the sun is captured by solar panels and transformed into heating or, by means of photovoltaic (PV) systems, into electricity. The use of solar technologies is growing worldwide: large scale solar radiation maps (e.g. SOLEMI [1], SoDa [2], PVGIS [3]) are already published on-line; at urban scale some municipalities are starting to build city solar atlases (e.g. Hamburg [4], Berlin [6]) in order to increase or create the demand of photovoltaic and thermal panels (Ludwig and McKinley, 2010). The identification of suitable surfaces in urban areas plays therefore an important role both for the private investor and the public local community. Due to the complexity of this task, quality of solar radiation predictive models, as well as quality and quantity of their input data are pivotal to optimally exploit the advantages of solar panel systems. Indeed they need to be properly located and oriented in the environment to meet the required specifications (insolation time, area orientation, panel type, characteristics of power network, etc.).

Among all factors influencing a correct estimation of the incoming solar radiation, it is crucial to consider shadowing effects due to topography (presence of hills/mountains) or shadows cast by nearby buildings, vegetation or other objects found in urban areas (Ike and Kurokawa, 2005).

The accuracy and Level of Detail (LoD) of the geometric models used to represent buildings (or their roofs) is also important, since complex geometries - like in case of dormers or chimneys - must be considered in order to produce accurate solar radiation maps. The need of geometric accuracy, on one hand, and the variety of scales to be considered - from architectural to regional -, on the other hand, tend to be diverging forces, so that often a compromise has to be found. In the following, two examples are given to exemplify the two main research paradigms, which the method described in this paper is trying to unify.

a) PVGIS (Photovoltaic Geographical Information System) provides a map-based inventory of solar energy resources and assessment of the electricity generation from PV systems in Europe, Africa and South-West Asia (Š́ri et al., 2006). For the European subcontinent it delivers, among other products, the daily sum of global radiation and the theoretical optimum inclination angle of PV modules to maximize energy yield production: data are presented as raster layers at a resolution of $1 \times 1 \mathrm{~km}$.

b) Jochem et al. (2009) focus instead on the automatic identification, segmentation and analysis of roof shapes/facets from a dense LiDAR dataset $\left(17\right.$ points $\left./ \mathrm{m}^{2}\right)$ in a study area of $0.3 \mathrm{~km}^{2}$. Transparent shadow values for nearby vegetation are introduced and the full 3D information of the point cloud is used for both solar potential assessment and modelling of shadowing effects of nearby objects. The shadowing effect due to terrain is not directly considered, but included through the use the CSI (clear sky index) as a model of cloud-cover effects.

The work presented in this paper sits probably between these two research directions: the first goal is to test the feasibility of a solar radiation estimation methodology based on geometric data ranging from regional to architectural scale. Several roof models, obtained by different surveying/modelling techniques and with varying LoD, are embedded in a DTM of an Alpine

\footnotetext{
* Corresponding author. Full address: 3DOM, FBK - Fondazione Bruno Kessler, Via Sommarive 18, 38123 Povo - Trento, Italy.
} 
valley surrounded by mountains, so that both the terrain and the nearby building shadowing effects are considered. Additionally, the solar radiation maps obtained from the different geometric models are compared and evaluated in order to gain information on benefits/disadvantages tied to each model.

The solar radiation estimation is performed within the GRASS GIS environment (Neteler and Mitasova, 2007) using r.sun and its ancillary modules. The open-source algorithms implemented in r.sun by Hofierka and Š́ri (2002) are wellknown and tested in a variety of studies, e.g. in Kryza et al. (2010); Nguyen et al. (2009) use r.sun to compute insolation including temporal and spatial variation of albedo and solar photovoltaic yield. All steps from data acquisition and preprocessing to post-simulation are presented, whereby candidate lands for incoming solar farms projects are identified.

Hofierka and Kanuk (2009) discuss a methodology for the assessment of photovoltaic potential in urban areas using opensource solar radiation tools and a 3D city model implemented in a GIS. The test area extends over ca. $3.7 \mathrm{~km}^{2}$, the solar radiation is calculated using the PVGIS estimations coupled with the city model roof geometries. A comparison with r.sun and using building models has highlighted discrepancies between the averaged values of PVGIS and the spatial variability of an urban environment due to the shadowing effects of nearby object.

\section{TEST AREA AND DATA SOURCES}

The test site for this study is located in Mattarello, an urban borough of Trento, the largest city in the Trentino-Alto Adige/Südtirol region (Northern Italy). The test site area lies few kilometres south of the city centre, on the eastern flank of the river Adige valley, and it is surrounded, mainly east and west, by the Alps, whereas the Adige valley stretches mainly north to south. The test area is approximately $1.5 \times 2.1 \mathrm{~km}$ wide, it contains circa 1300 residential, industrial and commercial buildings, with varying sizes and geometry complexity. Building location varies from the valley plane to hill top or on the flank of the Alps (Figure 1).

The dataset was derived from heterogeneous data sources, although at different levels of detail and covering different extents. Most of the used data were provided by the Autonomous Province of Trento (PAT). The datasets consist of: a vector cadastral map, at nominal scale of 1:1000, containing all building footprints and some external attributes, including the average building height. Since roofs are not modelled in the cadastral map, flat roofs were rasterised using the average height value of the building. The footprints served also in the next analyses as surface unit for each building: although rasterisation can introduce errors in the estimation of the total irradiated roof size (e.g. due to roof overhangs), this approach provides a standardised common reference for all geometry models employed in this work.

a raster-based DSM (and the resulting DTM), at a nominal scale of 1:10000, of the whole province, calculated from a LiDAR flight in 2006/7. Height accuracy for the original LiDAR data is given as $\sigma_{\mathrm{z}}=15 \mathrm{~cm}$ for the DSM, and $\sigma_{\mathrm{z}}=30$ $\mathrm{cm}$ for the DTM. Both DSM and DTM are delivered already post-processed, geo-referenced and rasterised. For the study area, raster tiles of $2 \mathrm{~km}$ side can be downloaded at $1 \times 1 \mathrm{~m}$ resolutions. The DTM of a larger area surrounding Mattarello, of approximately $16 \times 18 \mathrm{~km}$ and at
$1 \mathrm{~m}$ resolution, was used in the successive computation of the horizon maps, i.e. considering adjacent mountains (as high as $1900 \mathrm{~m}$ ) and the resulting shadowing effect.

nadir aerial images acquired from a helicopter in 2009 with a calibrated Nikon D3X camera equipped with a 50 $\mathrm{mm}$ lens. The images have an average ground sample distance (GSD) of circa $10 \mathrm{~cm}$ and were triangulated and geo-referenced in ERDAS/LPS using 6 GCPs measured with sub-decimetre accuracy by means of GNSS a receiver. From the aerial images, four different models were extracted: two DSMs, at $1 \mathrm{~m}$ and $25 \mathrm{~cm}$ resolution respectively, generated automatically with SAT-PP [6]; the exported vector 3Dfaces of 30 manually measured roofs, modelled in PhotoModeler [7], were rasterised to produce the last two datasets, at $1 \mathrm{~m}$ and $25 \mathrm{~cm}$ resolution, respectively.

Six raster models of the study area were generated and used for the solar radiation estimation in the test area:

a) a raster of flat roofs derived from the cadastral map,

b) a raster with roofs extracted from the LiDAR-based normalised DSM overlapping the cadastral map;

c) a raster with roofs obtained from the automatic matching of aerial images;

d) a raster with roofs obtained using PhotoModeler;

e) an analogous raster to c) but rasterised at higher grid resolution;

f) an analogous raster to d) but rasterised at higher grid resolution.

Rasters a), b), c) and d) are at $1 \mathrm{~m}$ resolution; e) and f) at 25 $\mathrm{cm}$ resolution. All rasters were embedded in the DTM (embedding of the rasters at $25 \mathrm{~cm}$ resolution required DTM oversampling). All raster models were compared with each other in order to identify and exclude those buildings which have been changed, demolished or built in the time interval between different data acquisitions. A detail view of all six rasters is given in Figure 2.

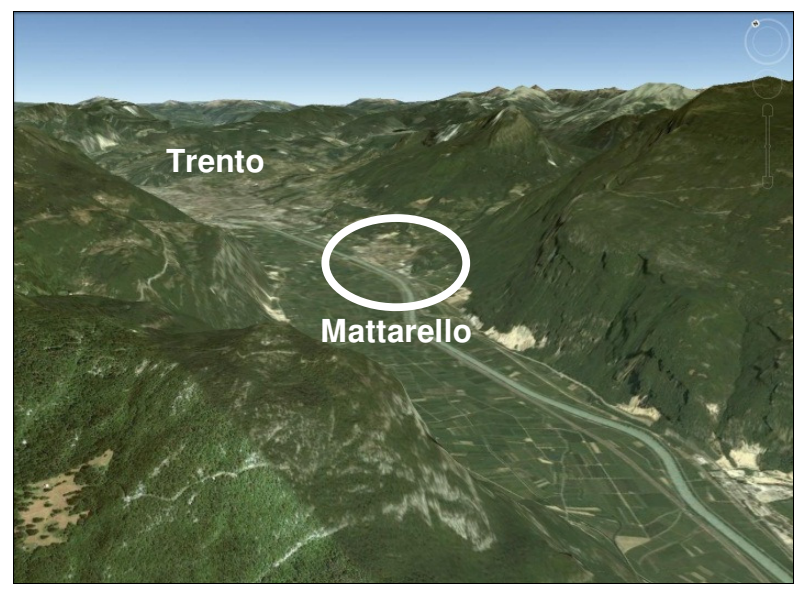

Figure 1 - Aerial view (Google Earth) of the Adige valley in the Alps, with the location of the test site: Mattarello, Trento, Italy.

\section{ESTIMATION OF THE SOLAR RADIATION}

Š́ri and Hofierka (2004) identified three main factors determining the interaction of the solar radiation with the Earth's atmosphere and surface. The first one depends on the terrestrial geometry, i.e. the rotation and revolution of our 
a) Cadastral, flat roof model (res. $1 \mathrm{~m}$ )
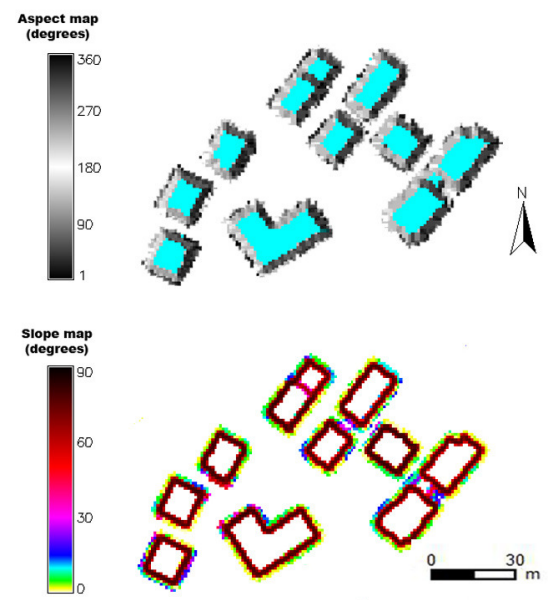

d) Manual reconstruction model (res. $1 \mathrm{~m}$ )
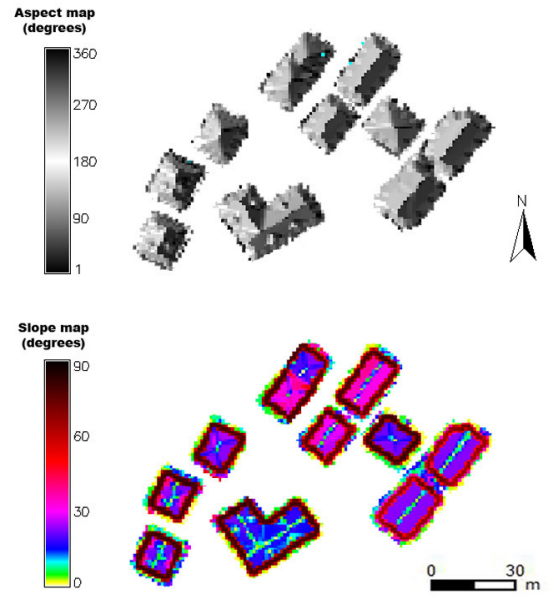

b) LiDAR-based model (res. $1 \mathrm{~m})$
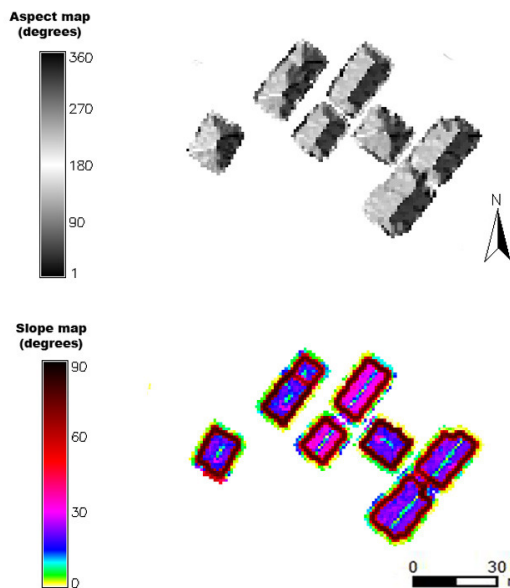

c) Automatic image matching model (res. $1 \mathrm{~m}$ )
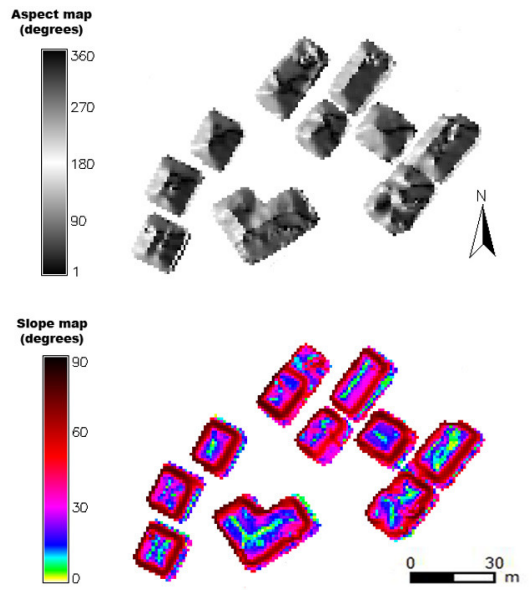

e) Automatic image matching model (res. $25 \mathrm{~cm}$ ) f) Manual reconstruction model (res. $25 \mathrm{~cm}$ )

Figure 2 - Raster maps obtained from different data for building roofs. Aspect and slope maps of a group of buildings in the test area, obtained from: a) cadastral maps (flat roofs), b) LiDAR-based DSM, c) automatic matching of aerial images, d) manual reconstruction from aerial images, e) automatic matching of aerial images (rasterised at grid resolution $25 \mathrm{~cm}$ ), f) manual reconstruction from aerial images (rasterised at grid resolution $25 \mathrm{~cm}$ ). Aspect maps are classified starting from east, counter clockwise (north $=90^{\circ}$, west $=180^{\circ}$, south $=270^{\circ}$ ), areas in cyan are horizontal. Some roofs are missing in b) since not yet built at the time of the LiDAR flight. Terrain data (except a thin buffer zone) has been masked out in order to facilitate visualisation.

planet around the sun, which determines the available extraterrestrial radiation based on solar position above horizon. Secondly, the terrain surface, i.e. the slope, the aspect and shadowing effects of the surrounding terrain features can modify the radiation distribution to the Earth's surface. Finally, the atmosphere is composed by gases, clouds, solid and liquid particles, which all lead to a certain attenuation in terms of global radiation.

In GRASS GIS, the r.sun module allows to model all above mentioned factors, although at different levels of accuracy.

The geometric factors (astronomic and terrestrial ones) can be modelled quite efficiently, while the atmospheric attenuation can be handled only with a certain level of accuracy. More specifically, r.sun computes direct, diffuse and ground reflected solar radiation maps for a given day, latitude, surface and atmospheric conditions, using built-in solar parameters (e.g. time of sunrise and sunset, declination, extra-terrestrial irradiance, daylight length). The model computes radiation for the clear sky conditions, thus it does not take into consideration the spatial and temporal variation of clouds. Average monthly values of the air turbidity coefficients (Linke data) can be provided as a single value or as input raster maps: in this study the Linke data were obtained from the SoDa site [2] as a global dataset, then reprojected and resampled to the local coordinate system.

The shadowing effect of the topography can also be incorporated. It is achieved in two ways: it is calculated directly by r.sun from the digital elevation model or, alternatively, rasters of the horizon height are used. Horizon maps are pre-computed only once, so their use speeds up r.sun operations considerably (this second approach is preferable in case of multiple simulations). The GRASS module r.horizon is 
used to iteratively compute horizon maps for a given area, in that $n$ maps are created for $n$ directions: for each cell, the horizon height angle is stored for the given direction in a map. Moreover, although horizon raster are needed only for the study area (i.e. approximately $1 \times 2 \mathrm{~km}$ ), r.horizon allows to extend the computation area to larger parts of the surrounding DTM, thus including shadow-casting mountains around the test site. In this study, 24 horizon maps were computed for each geometric model, thus at $15^{\circ}$ intervals. This was the most demanding step in the whole pipeline: all computations were carried out on a $3 \mathrm{GHz}$ dual-core machine, with $8 \mathrm{~GB}$ of RAM and running a 64 bit version of Linux and GRASS GIS 64 bit. Computation of 24 horizon maps at $1 \mathrm{~m}$ grid resolution took approximately 10 hours, while the time needed for a $25 \mathrm{~cm}$ model was about 3.5 days.

Once the elevation model, its aspect and slope maps, the Linke turbidity and the horizon maps are prepared, solar radiation can be computed using r.sun. More specifically, several radiation maps were obtained in this work: for each geometric model, direct, diffuse and global radiation maps were calculated, yielding the average radiation value (in $\mathrm{Wh} / \mathrm{m}^{2} / \mathrm{d}$ ) for each month. The yearly average value was also calculated.

\subsection{Calibration of r.sun}

In order to calibrate the global radiation model, real data collected in the past 10 years (2001-2010) from a pyranometer, located on the roof of an industrial building next to the study area were used. The availability of solar radiation flux density values $\left(\mathrm{W} / \mathrm{m}^{2}\right)$ sampled every 15 minutes allowed to compute daily clear sky global radiation (GR) values at the pyranometer position using r.sun with the following inputs: a) the DSM of the area, including the shadow-casting nearby mountains, b) horizons maps with an angle step of $20^{\circ}$, c) Linke data previously described. Furthermore, the pyranometer data were aggregated in order to obtain a daily global radiation values.

Since cloud cover information is not available, the daily maximum values (MV) over the ten years observation interval were used as observed values for clear sky solar irradiation.

By means of the normalised mean bias (NMB) index, under- or overestimations of the model can be quantified as follows on a monthly basis ( $\mathrm{N}=$ days per month):

$$
N M B=\frac{\sum_{i=1}^{N}\left(M V_{i}-G R_{i}\right)}{\sum_{i=1}^{N} G R_{i}}
$$

The NMB index was computed along the 10 years for December, March and July. The model was found to underestimate in December (-20.5\%) and overestimate in July (12\%), respectively. A good correspondence between estimated and observed values was found in March $(0.2 \%)$.

\subsection{Solar radiation and roof models}

Multiple r.sun simulations were run stating from the six different rasters (see section 2) and the accompanying data (slope, aspect, horizon maps). Direct radiation, instead of global radiation, was chosen for these analyses, since it is mostly affected by the shadowing. On all resulting maps, yielding the monthly average direct solar radiation expressed in $\mathrm{Wh} / \mathrm{m}^{2} / \mathrm{d}$, cell values were aggregated using the cadastral footprints as aggregation area. For each building, comparable minimum, maximum and average values of direct radiation were obtained, in order to compare the different simulation results.
An initial test was performed to check the influence of the shadowing effect: radiation maps were calculated from the LiDAR-based raster, without inclusion of the terrain shadowing effect. In general, the shadowing effect due to the topography led to lower values of solar radiation, as expected: on a year basis, differences between homologous roofs (with and without terrain shadowing) are up to $8 \%$ on some buildings; on monthly basis, differences can reach peaks of $38 \%$ during the winter months (December and January).

Taking the whole dataset into account for rasters of type a) and b) (see Figure 3), radiation results for the cadastral flat roofs are consistently higher than for LiDAR-based roofs by $4.0 \%$ on a year basis. The difference has a minimum in December (2.0\%) and a maximum in June (4.5\%). Results are plotted in the graph of Figure 3.

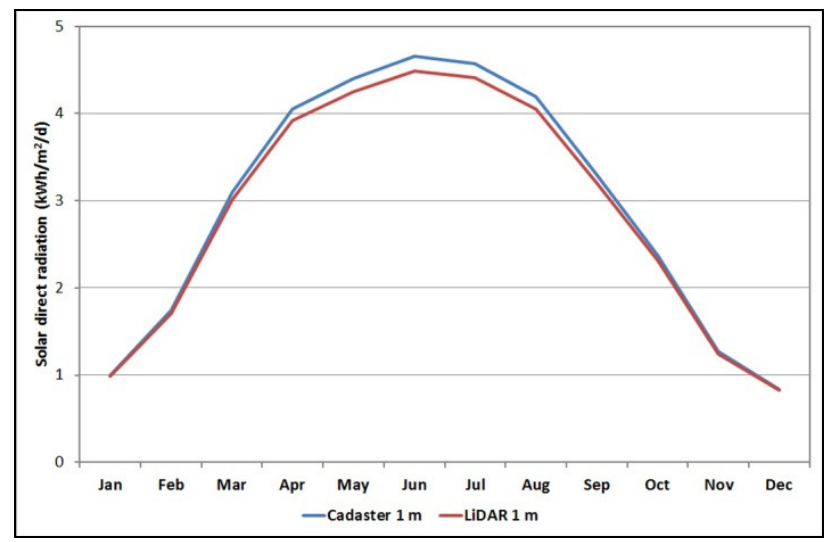

Figure 3 - Monthly solar radiation values from cadastral and LiDAR-based roof models, obtained averaging results from all 1300 buildings in the test area.

The analysis was replicated on the same dataset, distinguishing however between large industrial/commercial buildings (which tend to have a quite regular geometry and flat roofs) and smaller residential buildings, whose roof geometries may be more variable. A smaller difference of $1-2 \%$ on a year basis was found for non-residential buildings than for residential ones (4-6\% on a year basis). In the latter case LiDAR-based roofs had peak differences of $13 \%$ per year. An example showing results from an industrial and a residential building is shown in Figure 4.

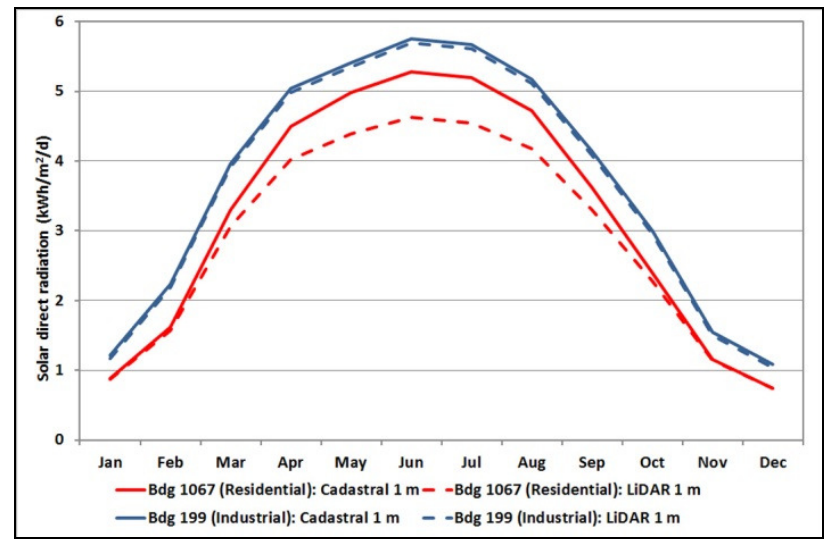

Figure 4 - Comparison between solar radiation results obtained for two different building classes. In case of an industrial building, cadastral and LiDAR-based roofs deliver similar results (average difference $1.9 \%$ on a year basis). For a residential building, results differ more (average difference 
$9.6 \%$ on a year basis, maximum difference in June, $12.4 \%$, minimum difference in December, $0.1 \%$ ).

For a subset of 21 residential buildings, rasters of all other types c ), d), e) and f) were computed, thus including the effect of different methods and scales in the automatic matching and manual reconstruction process. A comparative analysis was performed by using at first only results from rasters at $1 \mathrm{~m}$ resolution, then including also those obtained at $25 \mathrm{~cm}$ resolution.

At $1 \mathrm{~m}$ spatial resolution, comparing automatic image matching to manual reconstruction, it was found that roof models from LiDAR data deliver fairly similar results, while a higher difference was found for cadastral flat roofs, as in the previous experiment. Taking the LiDAR-based roof results as reference, yearly average differences account for: $-2.1 \%$ manual reconstruction models, $0.9 \%$ automatic matching models, and $6.9 \%$ cadastral roof models. The monthly average solar radiation values for all models are represented and plotted in the graph of Figure 5.

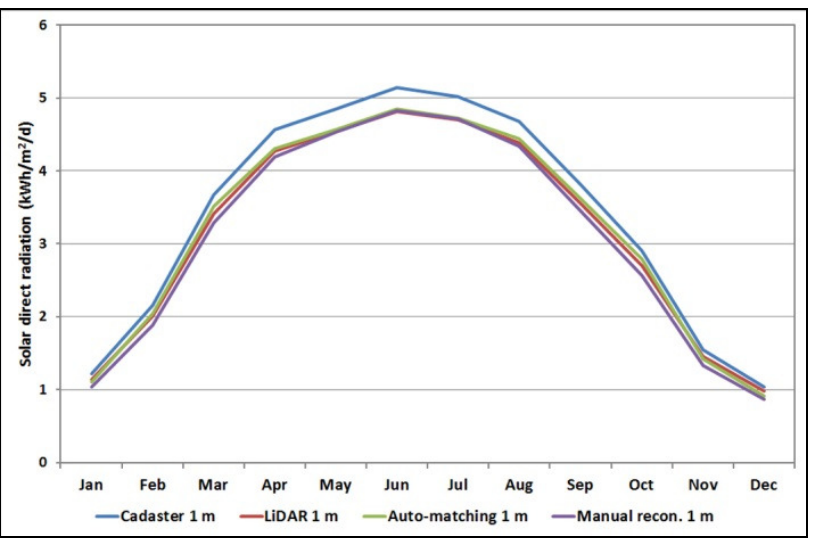

Figure 5 - Comparison between solar radiation results obtained from all rasters at $1 \mathrm{~m}$ resolution.

At $25 \mathrm{~cm}$ spatial resolution, results show that roofs modelled by automatic image matching yield the lowest solar estimate of radiation. Manually modelled roofs lead instead to values of solar radiation that, during the summer months, are closer to those of the cadastral flat roofs. Taking again the LiDAR-based roof results as reference, yearly average differences account for $1.8 \%$ in manual reconstruction models and $-11.3 \%$ in automatic image matching models. In Figure 6 results from the $25 \mathrm{~cm}$ resolution rasters are plotted over the same data of Figure 5.

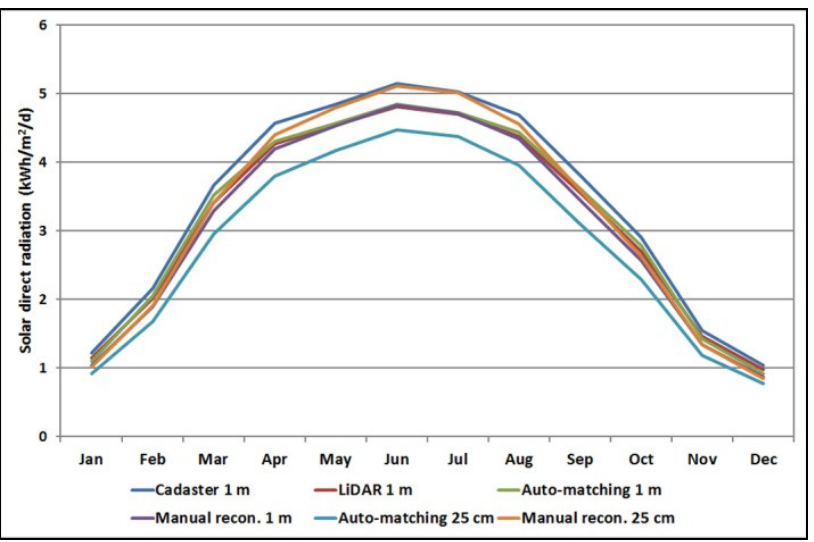

Figure 6 - Comparison between solar radiation results obtained from all rasters, at $1 \mathrm{~m}$ and $25 \mathrm{~cm}$ resolution. Data at $1 \mathrm{~m}$ resolution are the same as in Figure 5.

Although a subset of 21 roof models is still numerically too small if compared with the whole dataset of 1300 buildings and therefore the following considerations must be taken with care and are subject to further testing -, comparative analyses suggest the following comments to the results obtained so far:

a) As long as solar radiation estimation are carried out on small to mid-size residential buildings, there are no substantial differences in the output among rasters at $1 \mathrm{~m}$ resolution models obtained from the LiDAR-based DSM, the automatic image matching and the manual modelling process. The cadastral flat roof models tend instead to deliver higher values of direct solar radiation. Therefore, the more time-consuming manual modelling could be avoided whenever other data-sources are already available at such resolution.

b) When using rasters at $25 \mathrm{~cm}$ resolution obtained from manually modelled roofs, results are again comparable with those at $1 \mathrm{~m}$ resolution (except flat roofs). The reason for higher values of solar radiation in the summer months is still subject of investigation, although one possible explanation could be the absence of chimneys in the PhotoModeler reconstructions: such a roof surface is therefore not affected by their shadowing effect.

c) When using rasters at $25 \mathrm{~cm}$ obtained from automatic image matching models, values of solar radiation are considerably lower than those obtained at $1 \mathrm{~m}$. Although the reason is still under examination, this could be due to noise introduced by the auto-correlation algorithms on otherwise planar roof surfaces during the DSM extraction. This is best seen in Figure 7: the original roof facets are quite regular (there is only one chimney), nevertheless the resulting DSM is not correctly modelled and might be affected by "auto-shadowing".
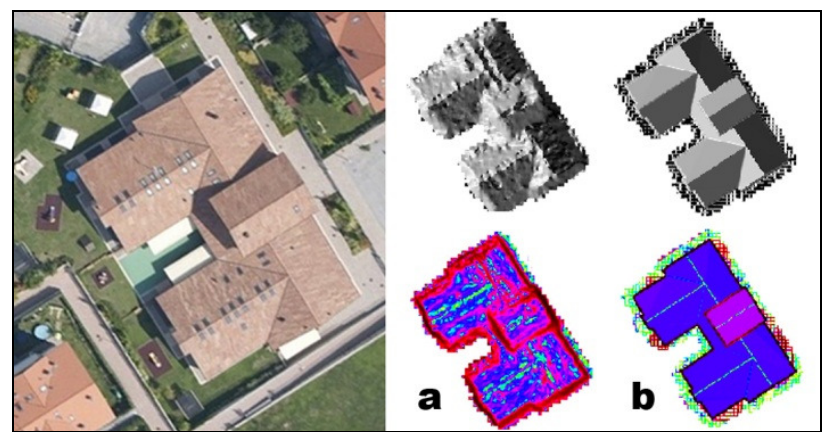

Figure 7 - Comparison between rasters at $25 \mathrm{~cm}$ resolution of the same building, presented in the left image: aspect (top) and slope (bottom) maps of the same building obtained from photogrammetry: automatic matching (a) and manual reconstruction (b). Legends for aspect and slope are as in Figure 2.

\section{CONCLUSIONS AND OUTLOOK}

In this work, different roof models have been rasterised and integrated onto a regularised DTM for the estimation of the solar radiation: flat roofs from cadastral datasets, LiDAR-based DSM roof surfaces, as well as models obtained from automatic and manual image matching. All models have their own peculiarities in terms of geometric resolution and accuracy and 
deliver slightly different results. However, they all represent a step forward compared to the otherwise available solar radiation estimation models in terms of geometric accuracy for the Trento area: from the PVGIS raster based analyses at $1 \mathrm{~km}$ grid cell size, it now possible to perform solar radiance simulations on roofs at resolutions ranging from $1 \mathrm{~m}$ to $25 \mathrm{~cm}$. The test site has been chosen due to the availability of heterogeneous datasets, its complex topographic characteristics (i.e. a valley between high mountains) and the presence of already installed solar panels which guarantee real data to be used as reference for global solar radiation.

In the computation process, shadows cast by the surrounding mountains have been considered.

For every raster obtained from a distinct data source, monthly average solar direct radiation maps have been obtained, in order to perform a comparison among the results of homologous buildings. Radiation maps obtained with rasters at $1 \mathrm{~m}$ resolution show, in general, that results from the LiDARbased roofs and those from automatic image matching and manual modelling deliver comparable results. The flat roof models from cadastral maps tend to provide higher estimations of solar radiation, however they can be used as well in case of big industrial or commercial buildings with fairly regular and planar roofs.

When it comes to the analyses of the 25-cm-resolution rasters, it must be primarily noted that more high-resolution models are needed to perform further tests. Nevertheless, the initial results indicate that the roof models obtained from automatic image matching do not lead to results similar to those from other models. More specifically, direct solar radiation values are generally underestimated by circa $10 \%$.

Several are the future planned enhancements and possible extensions to the presented approach. First of all, no shadowing effect from nearby vegetation is yet integrated in the pipeline; however this could be achieved using data from the DSM, at least as long as no other better data sources are given.

In general, solar radiation results obtained so far lack a proper comparison with reference data of incoming solar energy. This is due to the fact that solar panel installations on private houses are generally mounted without any pyranometer. Often, even a data-logger to record the resulting electricity production is missing or sold optionally. Nevertheless, validation of the r.sun model could be carried out using data being logged from existing PV industrial installations next to the study area.

Moreover, r.sun already implements the possibility to further refine/reduce the clear-sky radiation by means of proper atmospheric correction coefficients (e.g. cloudiness), however these values derive from long-term meteorological measurements and must be provided separately for direct and diffuse radiation (Š́ri and Hofierka, 2004).

All analyses so far are expressed in in $\mathrm{Wh} / \mathrm{m}^{2} / \mathrm{d}$ and averaged over the whole footprint of the building. This is of course a strong simplification, since no segmentation has been carried out yet on the existing datasets to identify the distinct roof facets. On the other hand, this allows to deliver comparable results from heterogeneous datasets in a relatively fast and nearly completely automated way.

It must be noted that very dense and accurate geometric data is surely needed to model complex roof geometries (e.g. chimneys and dormers), otherwise the effort of high resolution analyses may not be worth.
It could be therefore interesting to test this methodology on an existing, detailed and already segmented city model (e.g. CityGML LoD 2 or 3) (Kolbe, 2009). Starting from such a spatio-semantic rich model could help the automation process to model the solar radiation (and thus PV potential) for all urban objects, providing furthermore local authorities with a powerful planning and information tool.

\section{REFERENCES}

Hofierka, J., Kanuk, J., 2009: Assessment of photovoltaic potential in urban areas using open-source solar radiation tools. In: Renewable Energy, Vol. 34(10), pp. 2206-2214.

Hofierka, J., Šúri, M., 2002: The solar radiation model for Open source GIS: implementation and applications. In: Manuscript submitted to the International GRASS users conference in Trento, Italy.

Ike, S., Kurokawa, K., 2005: Photogrammetric estimation of shading impacts on photovoltaic systems. In: 31st Photovoltaic Specialists Conference, IEEE, 3-7 Jan. 2005, pp. 1796-1799.

Jochem, A., Höfle, B., Hollaus, M., Rutzinger, M., 2009: Object detection in airborne LIDAR data for improved solar radiation modeling in urban areas. In: International Archives of Photogrammetry, Remote Sensing and Spatial Information Sciences. Paris, Vol. 38 (part 3/W8), pp. 1-6.

Kolbe, T, 2009: Representing and exchanging 3D City Models with CityGML. In: Proceedings of the 3rd International Workshop on 3D Geo-Information, Lecture Notes in Geoinformation \& Cartography, Seoul, Korea, Springer Verlag, p. 20.

Kryza, M., Szymanowski, M., Migala, K., et al., 2010: Spatial information on total solar radiation: Application and evaluation of the r.sun model for the Wedel Jarlsberg Land, Svalbard. In: Polish Polar Research, Vol. 31(1), pp. 17-32.

Ludwig, D., McKinley L., 2010: Solar Atlas of Berlin - Airborne Lidar in Renewable Energy Applications. In: GIM International, Vol. 24 3/2010, pp.17-22.

Neteler, M., Mitasova, H., 2007: Open Source GIS: A GRASS GIS Approach. Third edition. Springer, New York, ISBN-10: 038735767X; ISBN-13: 978-0387357676.

Nguyen, H.T., Pearce, J.M., 2010: Estimating potential photovoltaic yield with r.sun and the open source Geographical Resources Analysis Support System. In: Solar Energy, Vol 84(5), pp. 831-843.

Súri, M., Hofierka, J., 2004: A new GIS-based solar radiation model and its application to photovoltaic assessments. In: Transactions in GIS 8, pp. 175-190.

Š́ri, M., Huld, T., Dunlop, E.D., Albuisson, M., Wald, L., 2006: Online data and tools for estimation of solar electricity in Africa: the PVGIS approach. In: Proceedings of the 21st European Photovoltaic Solar Energy Conference and Exhibition, 4-8 October 2006, Dresden, Germany.

\section{REFERENCES FROM WEBSITES}

1, http://www.solemi.com (Last visit: 29 June 2011)

2, http://www.soda-is.com (Last visit: 29 June 2011)

3, http://re.jrc.ec.europa.eu/pvgis (Last visit: 29 June 2011)

4, http://www.hamburgenergiesolar.de (Last visit: 29 June 2011)

5, http://www.businesslocationcenter.de/en/3d/A/i/1/seite0.jsp (Last visit: 29 June 2011)

6, http://www.4dixplorer.com/software_satpp.html (Last visit: 29 June 2011)

7, http://www.photomodeler.com (Last visit: 29 June 2011)

\section{ACKNOWLEDGEMENTS}

The presented work was partly supported by the ENERBUILD project within the Alpine Space Program (11-2-1-AT). The authors would also like to thank the Autonomous Province of Trento (PAT), which kindly provided most of the employed spatial data. Thanks are also due to Unifarm for providing solar radiation data logged by the pyranometer, as well as to Shamar Droghetti and Andrea Gobbi (FBK Trento) for valuable help during the data processing and model validation. 